\title{
Comparativeanalysis of two catalytically distinct endoglucanases from Aspergillus nidulans
}

\author{
Baljit Kaur ${ }^{1}$, H.S. Oberoi ${ }^{2}$, B.S. Chadha ${ }^{1 *}$ \\ ${ }^{1}$ Department of Microbiology, Guru Nanak Dev University, Amritsar-143 005, India. \\ ${ }^{2}$ Post Harvesting Technology, Indian Institute of Horticulture Research, Bengaluru-560089, Karnatka, India.
}

\section{ARTICLE INFO}

Article history:

Received on: 30/03/2015

Revised on: 11/04/2015

Accepted on: 23/04/2015

Available online: 27/04/2015

Key words.

Thermoacidophilic

endoglucanases, GH7, GH12,

barley $\beta$-glucan

\begin{abstract}
This study reports purification and characterization of two catalytically distinct endoglucanases (EGI and EGII) from a thermotolerant fungus Aspergillus nidulans. The endoglucanases (EGI and EGII) exhibited molecular masses of 56 and $31 \mathrm{kDa}$ and pIs of 3.6 and 3.8, respectively. EGI was putatively classified as GH7 family member catalyzed carboxymethyl cellulose, xyloglucan, barley $\beta$-glucan as well as pNP- $\beta$-D-lactopyranoside and pNP-cellobioside, and was optimally active at $50^{\circ} \mathrm{C}$ and $\mathrm{pH} 4.0$. Whereas, EGII lacking CBD preferentially recognized barley $\beta$-glucan when compared substrate CMC, xyloglucan and lichenan and was putatively classified as GH12 member. Interestingly, EGII was characterized to be thermoacidophilic exhibiting $96 \%$ its activity at $\mathrm{pH} 2.0$ and at $60^{\circ} \mathrm{C}$. Hydrolysis of barley $\beta$-glucan and CMC by EGI and EGII liberated cellobiose as a major product. HPLC analysis showed that barley $\beta$-glucan hydrolysate obtained by action of EGI showed high levels of glucose in addition to cellobiose indicating towards an exo type action of this enzyme.
\end{abstract}

\section{INTRODUCTION}

Cellulose has a great potential as a renewable energy source and has gained interest of biotechnology community on their exploration for biofuel production and other value added products. Cellulose is a linear homo-polymer of D-glucose monomers linked together through $\beta-1-4$ glycosidic bonds and mainly forms the structural cell wall component in both the lower and higher plants [1]. The biodegradation of complex polymeric structure of cellulose is primarily attributed to multi-component enzyme system that works in a synergistic manner. These enzymes are comprises of endoglucanase (EC 3.2.1.74), which attack cellulose in amorphous zone and release oligomers, cellobiohydrolases (CBHI \& CBHII) (EC 3.2.1.91), that liberate cellobiose from reducing and non-reducing ends, and $\beta$ glucosidase (EC 3.2.1.21), which hydrolyze cellobiose to glucose [2]. Endoglucanases are widely classified on the basis of different characteristics into families GH 5, 6, 7, 8, 9, 12, 45 \& 74 [3]. Due to intensive research on the structural, catalytic and functional roles, both bacterial and fungal cellulases have led their use in various fields [4]; [5]. In addition to their potential use in the biofuel industry, for degradation of agro-residual waste into simple sugars which can be further fermented, cellulases are widely employed in increasing the yield of fruit juices, beer filtration, paper and pulp industry as well as improving animal feed stock [6]; [7]. With increasing demand for endoglucanases,

\footnotetext{
* Corresponding Author

E-mail: baljit_sohal@ rediffmail.com
}

identification of new EGs, especially thermoacidophilic, with good properties for improved performance is highly desirable [8]. Different endoglucanases from the same family show difference in their substrate specificity as well as different optimum $\mathrm{pH}$ and temperature and therefore needs to be characterized [9]. In the present study, we have reported the comparative analysis of two purified endoglucanases (EGI and EGII) from Aspergillus nidulans that exhibited higher affinity towards barley $\beta$-glucan when compared to CMC. The purified enzymes EGI and EGII putatively can be classified as member of family GH7 and GH12 respectively on the basis of their characterization. Enzymes belonging to family GH7 can be bifunctional i.e. exhibiting both "endo" \& "exo" type activities and possess the ability to degrade crystalline cellulose "processively" as they have tunnel like active sites [10].

\section{MATERIAL AND METHODS}

\subsection{Culture}

A thermotolerant fungal strain isolated from compositing soil was identified as Aspergillus nidulans on the basis of morphology and molecular characterization based on sequencing of ITSI-5.8S-ITSII amplified rDNA [11]. The fungus was grown and maintained on YpSs medium of the following composition (\% w/v), starch 1.5; yeast extract $0.4 ; \mathrm{KH}_{2} \mathrm{PO}_{4} 0.2$ $\mathrm{K}_{2} \mathrm{HPO}_{4} 0.23 ; \mathrm{MgSO} 4$ 0.05; Citric acid 0.057 and agar 2.0. 


\subsection{Production of endoglucanase}

The culture was grown on solidified production medium in Erlenmeyer flasks $(250 \mathrm{ml})$ containing $5 \mathrm{~g}$ ground sorghum straw as a carbon source and $15 \mathrm{ml}$ of basal medium of following composition (\% w/v) ; $\mathrm{KH}_{2} \mathrm{PO}_{4} 0.4 \%, \mathrm{CH}_{3} \mathrm{COONH}_{4} 0.45 \%$, and $\left(\mathrm{NH}_{4}\right)_{2} \mathrm{SO}_{4} 1.3 \%$ (pH 7.0). The Flasks were inoculated with $2 \mathrm{ml}$ of spore suspension $\left(10^{5}\right.$ spores $\left./ \mathrm{ml}\right)$ and incubated for seven days at $40^{\circ} \mathrm{C}$. The enzyme was harvested by adding $50 \mathrm{ml}$ of sodium citrate buffer $(50 \mathrm{mM}, \mathrm{pH} 6.0)$ to the flasks and kept at $40^{\circ} \mathrm{C}$ for 1 $\mathrm{h}$ under mild shaking. The resultant slurry was filtered through muslin cloth and centrifuged at $8000 \mathrm{xg}$ for $10 \mathrm{~min}$. The filtrate was desalted and concentrated using an Amicon ultrafiltration cell fitted a PES membrane (10 KDa cut off) and used for the purification of EG.

\subsection{Purification of Endoglucanase}

The concentrated sample was centrifuged $(10,000 \mathrm{X} \mathrm{g})$ for $30 \mathrm{~min}$ and was loaded onto Bioscale macroprep DEAEcartridge (Fast flow) column (Biorad), pre-equilibrated with $20 \mathrm{mM}$ Tris- $\mathrm{HCl}$ buffer ( $\mathrm{pH}$ 6.8). The Proteins were eluted first with equilibration buffer ( 2 bed volume) followed by linear gradient of $1 \mathrm{M} \mathrm{NaCl}$ gradient in $20 \mathrm{mM}$ Tris- $\mathrm{HCl}$ buffer $(\mathrm{pH} 6.8$ ) at flow rate of $1 \mathrm{ml} \mathrm{min-1} \mathrm{(AKTA} \mathrm{PRIME}{ }^{+}$, Biosciences). The collected fractions (10 $\mathrm{ml}$ each) were analysed for EG activity. Fractions corresponding to EG peak obtained during $\mathrm{NaCl}$ gradient elution were pooled, concentrated, equilibrated with $1.7 \mathrm{M}$ $\left(\mathrm{NH}_{4}\right)_{2} \mathrm{SO}_{4}$ in $50 \mathrm{mM}$ phosphate buffer $\mathrm{pH} 7.0$ and applied on to a phenyl sepharose ${ }^{\mathrm{TM}} 6$ fast flow (Amersham) hydrophobic interaction (HIC) column $(5 \mathrm{ml})$ that had been equilibrated with same buffer. The column was eluted with linear gradient of $\left(\mathrm{NH}_{4}\right)_{2} \mathrm{SO}_{4}(1.7 \mathrm{M}-0 \mathrm{M})$ in $50 \mathrm{mM}$ phosphate buffer $(\mathrm{pH} 7.0)$ at flow rate of $1 \mathrm{ml} \mathrm{min}^{-1}$.

The fractions containing endoglucanase activity were pooled and concentrated and then loaded on Biogel P-60 (BioRad) gel filtration column $(1.8 \mathrm{~cm} \times 90 \mathrm{~cm})$ which resulted in purified isoforms of endoglucanase.

\subsection{Protein estimation}

The protein in the fractions was determined by measuring the absorbance at $280 \mathrm{~nm}$ using Shimadzu-1240 spectrophotometer and a modified microtitre based Bradford method at $595 \mathrm{~nm}[12]$.

\subsection{Endoglucanase activity}

The EG activity was measured in terms of release of reducing sugars by the 3, 5 dinitrosalicyclic acid (DNS) method [13]. The reaction mixture $(1 \mathrm{ml})$ containing equal amounts of appropriately diluted enzyme and $1 \%(\mathrm{w} / \mathrm{v}) \mathrm{CMC}$ prepared in 0.05 $\mathrm{M}$ sodium citrate buffer, $\mathrm{pH} 6.0$, was incubated for $10 \mathrm{~min}$ at $50^{\circ} \mathrm{C}$. The reaction was stopped by addition of DNS followed by boiling and the developed color was read at $540 \mathrm{~nm}$ using a Novaspec II spectrophotometer (Pharmacia). The EG in fractions during purification was measured by taking $50 \mu \mathrm{l}$ of fraction and buffer and $0.5 \mathrm{ml}$ of substrate. One unit of enzyme activity is defined as amount of enzyme that librates $1 \mu \mathrm{mol}$ glucose min-1 (for EG) under the standard assay conditions.

\subsection{Characterization of the endoglucanase 2.7.1SDS-PAGE and isoelectric focusing}

The homogeneity and molecular mass (Mr) of EG were determined by $10 \%$ SDS-PAGE. The Mr of EG was determined using the plot of $\log \mathrm{Mr}$ of standard protein markers (Bangalore Genei, India) versus their relative mobility. To reveal the expression of purified EGI and II zymogram analysis was carried out [14]. The native molecular weight of the EG was estimated by gel filtration using Sephacryl HR-200. Isoelectric focusing (IEF) was performed using $5 \%$ acrylamide gel containing $2.4 \%$ broad $\mathrm{pH}$ range (2-11) ampholine carrier ampholyte (Serva). The cathode buffer contained lysine $2.9 \%(\mathrm{w} / \mathrm{v})$ and arginine $3.5 \%(\mathrm{w} / \mathrm{v})$, whereas, O-phosphoric acid (10mM) was used as anode buffer. Isoelectric focusing was carried out for $1 \mathrm{~h}$ each at constant voltage of $100 \mathrm{~V}$ and $200 \mathrm{~V}$ followed with $500 \mathrm{~V}$ for $30 \mathrm{~min}$. Upon completion, the gel was silver-stained and the pI of EG was determined using a plot of relative mobility of standard protein $\mathrm{pI}$ markers (Fluka) versus their $\mathrm{pI}$.

\subsubsection{Temperature and $\mathrm{pH}$ Optima and stability}

Optimal temperature was determined by assaying the EG activity against $\mathrm{CMC}(1 \% \mathrm{w} / \mathrm{v})$ between 30 and $80^{\circ} \mathrm{C}$. The optimal $\mathrm{pH}$ was determined by measuring the activity between $\mathrm{pH} 2.0$ and 10.0, using $50 \mathrm{mM} \mathrm{HCl-KCl}(\mathrm{pH} \mathrm{2.0)}$, acetate $(\mathrm{pH} 3.0-5.0)$, phosphate ( $\mathrm{pH}$ 6.0-8.0), and glycine $\mathrm{NaOH}(\mathrm{pH} 9.0-10.0)$ buffers at $50^{\circ} \mathrm{C}$. For the determination of temperature and $\mathrm{pH}$ stability, purified EG aliquots were pre-incubated at different temperatures and $\mathrm{pH}$ range for 0-240 min and assayed for residual activity.

\subsubsection{Effect of metal ions and additives}

The enzyme was pre-incubated in $10 \mathrm{mM}$ of $\mathrm{CuSO}_{4}$, $\mathrm{FeSO}_{4}, \mathrm{MgSO}_{4}, \mathrm{MnSO}_{4}, \mathrm{ZnSO}_{4}, \mathrm{CaCl}_{2}, \mathrm{NaCl}, \mathrm{KCl}$, DTT, EDTA, $\mathrm{SDS}, \beta$-mercaptoethanol and $\mathrm{NBS}$ for $30 \mathrm{~min}$ at room temperature and the residual activities were determined using $\mathrm{CMC}$ as substrate.

\subsubsection{Substrate Specificity}

Substrate specificity of purified EGI and EGII isoform was determined against polysaccharides CMC (low and high viscosity), barley- $\beta$-glucan, filter paper, polygalactouronic acid, xylan, Avicel, cellobiose, salicin, solka floc, sucrose, xyloglucan, laminarin, and lichenin (Sigma) was determined by incubating 1 $\mathrm{ml}$ reaction mixture containing $25 \mu \mathrm{l}$ enzyme, $475 \mu \mathrm{l}$ citrate buffer (50 mM, pH 6.0) and $500 \mu \mathrm{l}$ substrate $(1 \% \mathrm{w} / \mathrm{v})$ at $50^{\circ} \mathrm{C}$ for $1 \mathrm{~h}$. The reaction was stopped by the addition of $2 \mathrm{ml}$ DNS reagent and tubes were kept in boiling water bath for $10 \mathrm{~min}$. The developed colour was read at $540 \mathrm{~nm}$ using Novaspec II Spectrophotometer (Pharmacia). Activity of EGI and EGII against different aryl compounds pNP- $\beta$ - D-cellobioside, oNP- $\beta$-D-xylopyranoside, oNP- $\beta$-D-galactopyranoside, pNP- $\beta$-D-galactopyranoside, $\mathrm{pNP}-\alpha-$ galactopyranoside, pNP-xylopyranoside, pNP-glucopyranoside, 
pNP-arabinopyranoside $(3 \mathrm{mM})$ was determined using microtitre based method (Kaur et al 2014). A reaction mixture containing enzyme $(25 \mu \mathrm{l})$ was mixed with $50 \mu \mathrm{l}$ of sodium acetate buffer (50 $\mathrm{mM}, \mathrm{pH} \mathrm{5.0)}$ and $25 \mu \mathrm{l}$ of substrate and incubated at $50^{\circ} \mathrm{C}$ for $1 \mathrm{~h}$, the reaction was terminated by adding $100 \mu \mathrm{l}$ of $\mathrm{NaOH}$-glycine buffer (0.4 M, pH 10.8) and the developed yellow color was read at $405 \mathrm{~nm}$ using an ELISA Reader (BioRad).

\subsubsection{Enzyme Kinetics}

The Michaelis-Menten kinetic parameters $\left(\mathrm{K}_{\mathrm{m}}, \mathrm{V}_{\max }\right.$, and $\mathrm{K}_{\mathrm{cat}}$ for endoglucanase EGI was determined against CMC, xyloglucan and barley- $\beta$-glucan. Wheras, for EGII $\mathrm{K}_{\mathrm{m}}, \mathrm{V}_{\max }$, and $\mathrm{K}_{\text {cat }}$ was determined against $\mathrm{CMC}$ and barley- $\beta$-glucan using LineweaverBurk plot.

\subsection{Hydrolysis}

For enzymatic hydrolysis of $\mathrm{CMC}$ and barley $\beta$-glucan respectively, $900 \mu \mathrm{l}$ of $1 \%$ respective substrate prepared in sodium citrate buffer $(0.05 \mathrm{M}, \mathrm{pH} 6.0)$ was incubated with $100 \mu \mathrm{l}$ of pure EG at $50^{\circ} \mathrm{C}$ for $72 \mathrm{~h}$. Samples were freeze dried by lypholization and redissolved in distilled water. HPLC analysis was carried out with the DIONEX system (USA) equipped with a P680 pump, a thermostated column compartment (TCC) and a differential refractive index detector (RI-101, SHODEX). The column was maintained at $85^{\circ} \mathrm{C}$ with water as a mobile phase at aflow rate of $0.6 \mathrm{ml} / \mathrm{min}^{-1}[7]$.

\section{RESULTS}

Two distinct endoglucanases from a thermotolerant fungus Aspergillus nidulans, which exhibited maximal level of EG (180.9 Ug-1 substrate) after 7 days incubation (Fig 1) on sorghum straw containing solidified medium [15], were purified and characterized.

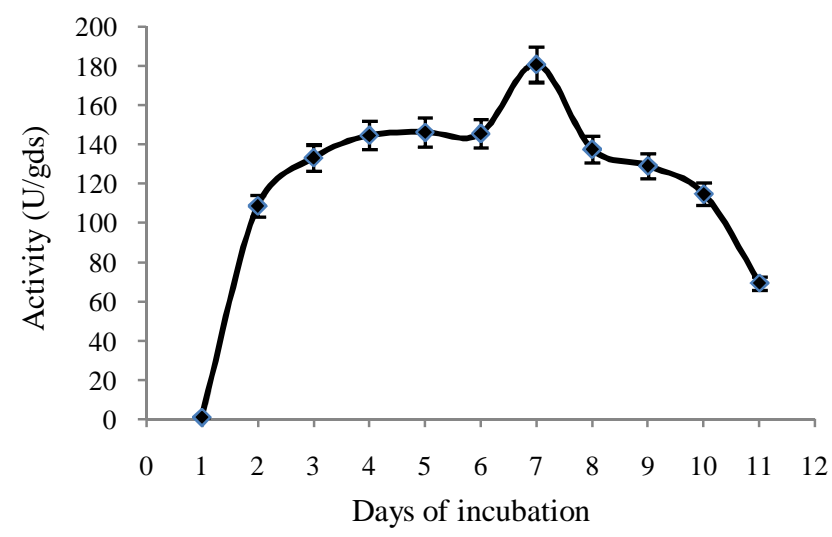

Fig1: Endoglucanase production profile of Aspergillus nidulans.

The purification of EGI and EGII involved ion exchange chromatography, which includes DEAE Sepharose followed by Phenyl sepharose (HIC) and gel filtration. Similar approaches have been employed for obtaining purified endoglucanase from Melanocarpus sp. and A.terreus [16]; [17]. During ion exchange chromatography the major EG containing fractions were eluted with $0.3-0.4 \mathrm{M} \mathrm{NaCl}$ gradient that were further fractionated on a phenyl-sepharose (HIC) column. Fractions corresponding to the major peak (I) were analyzed and found to be contaminated with CBH (Fig 2).

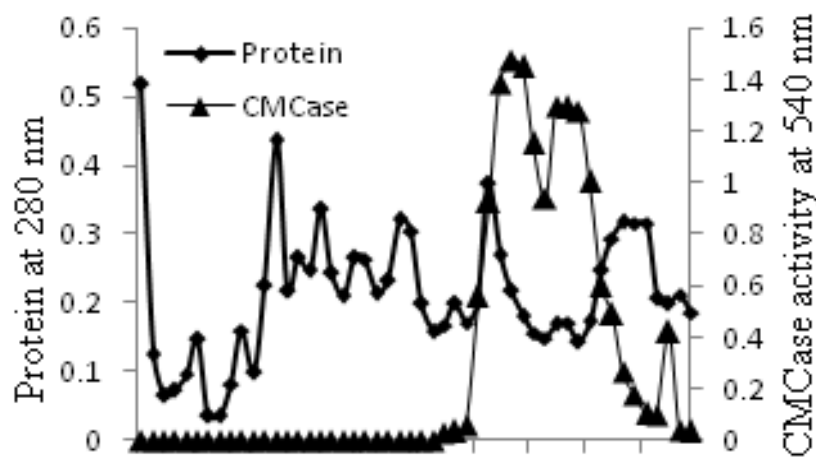

$\begin{array}{llllllllll}1 & 11 & 21 & 31 & 41 & 51 & 61 & 71 & 81 & 91\end{array}$

Fraction No.

(A)

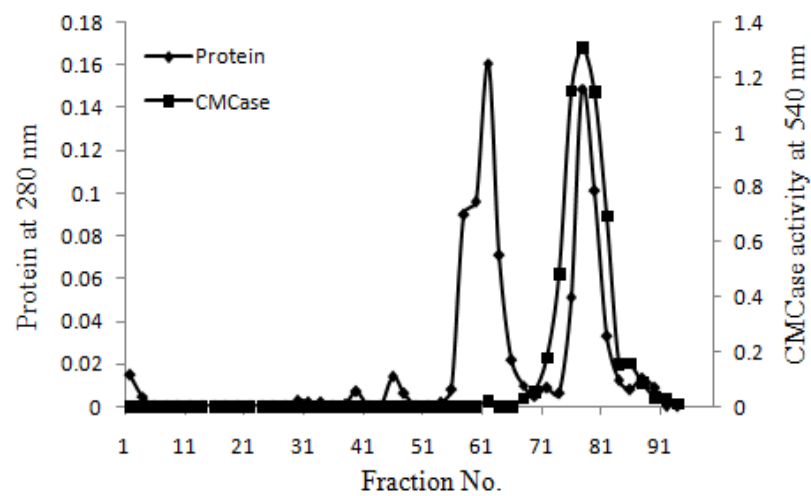

(B)

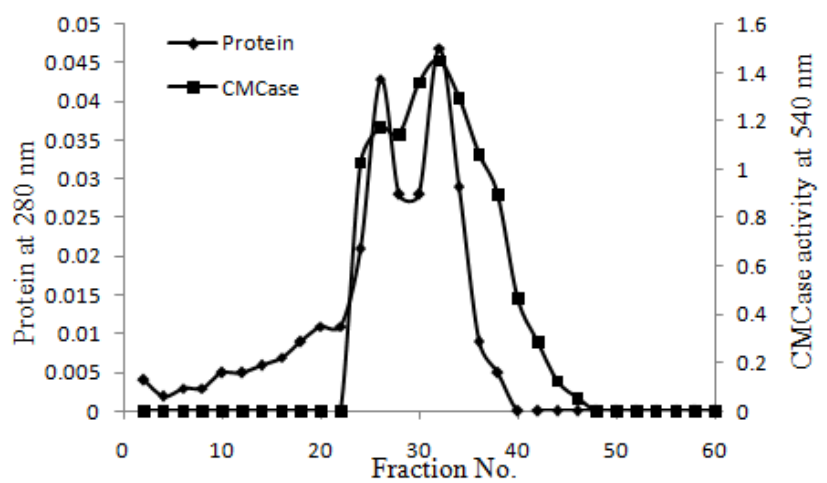

(C)

Fig. 2: Steps involved in purification of endoglucanase (EGI and EGII) from crude extract of Aspergillus nidulans (a) DEAE- Sepharose (b) PhenylSepharose (HIC) column (c) Biogel P-60.

Fractionation of this peak on a gel filtration column separated two isoforms of EG i.e. EGI and EGII which were further characterized. The purified EGI and EGII isoforms exhibited specific activity of $46 \mu \mathrm{mol} \mathrm{min}{ }^{-1} \mathrm{mg}$ protein ${ }^{-1}$ and $34.58 \mu \mathrm{mol}$ $\min ^{-1} \mathrm{mg}$ protein ${ }^{-1}$, respectively, with CMC as substrate. The 
enzymes EGI and EGII were purified by 12.98 and 8.75 folds, respectively. Both endoglucanase, EGI and EGII were apparently homogeneous on SDS-PAGE with molecular weight 56 and 31 $\mathrm{KDa}$ and showed pI of 3.6 and 3.8 respectively. The activity staining was carried out to ascertain the purified bands were EG (Fig3A-C) as described previously [17]. Endoglucanase purified from the diverse thermophilic microbial strains Melanocarpus sp., A. terreus and Penicillium pinophilum MS20 have been reported to have acidic pI [16]; [17]; [18].

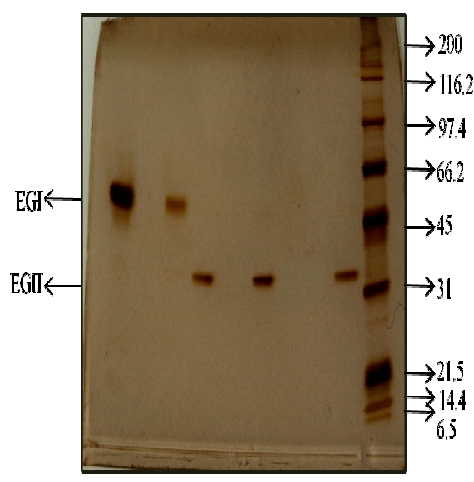

(A)

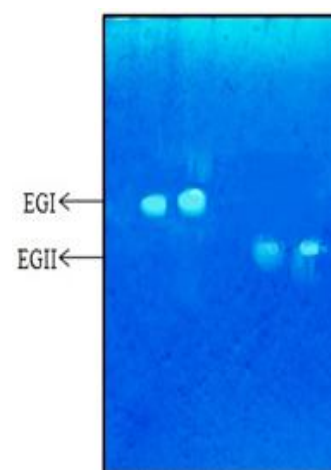

(B)

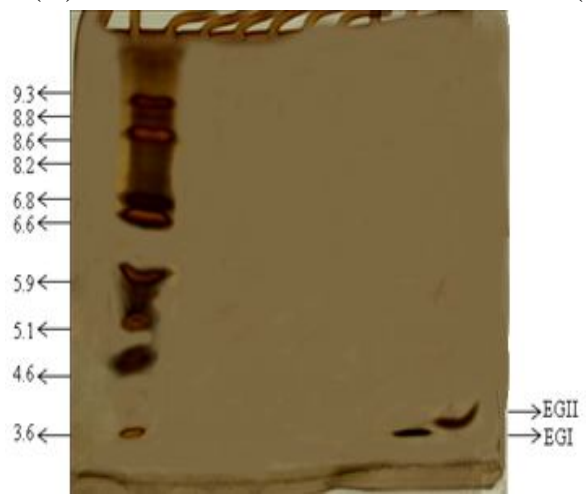

(C)

Fig. 3: SDS-PAGE (A) of purified isoforms of endoglucanase from Aspergillus nidulans Lane 1: EGI; Lane 2: EGII; Lane M: Standard protein markers in the order of increasing molecular mass: Aprotinin $(6.5 \mathrm{KDa})$; Lysozyme (14.4 KDa); Trypsin inhibitor (21.5KDa); Carbonic anhydrase (31 $\mathrm{KDa})$; Ovalbumin (45 KDa); Serum albumin (66.2 KDa); Phosphorylase b (97.4 KDa); $\beta$-galactosidase (116.2 KDa); Myosin (200KDa). (B) isoforms of endoglucanase (EGI and EGII) as revealed by activity staining resolved by SDS-PAGE. (C) Isoelectrofocussing of purified isoforms of endoglucanase Lane M: Standard pI markers (Sigma); Lane 1 EGI; Lane 2: EGII.

\subsection{Temperature, $\mathrm{pH}$ optima and stability}

EGI was optimally active at $50^{\circ} \mathrm{C}$ and at pH 5.0 (Fig4 a $\& 4$ b), however EGI showed $94.4,87.0$ and 80.9 of the activity at $\mathrm{pH} 7.0,8.0$ and 9.0 respectively, exhibiting broad $\mathrm{pH}$ range. Whereas EGII was highly active at $60^{\circ} \mathrm{C}$ at $\mathrm{pH} 3.0-6.0$ and retained $96 \%$ of the activity at as low as $\mathrm{pH} 2.0$ proving it to thermoacidostable. The results are in concurrence with the observations on other microbial cellulases reported by different workers [16]; [17]; [19]; [20]. Acidophilic cellulases have application in the non-ionic surfactant-assisted acidic deinking of mixed office waste [6]. Moreover, most of the reported EGs are fairly stable up to 40 and $50^{\circ} \mathrm{C}$, retaining greater than $80 \%$ of the original activity on CMC. Thermostability of the purified endoglucanases was also studied which is an important characteristic required for the industrial application of the enzymes. The stability of EGI at $\mathrm{pH} 5.0$ and 7.0 at temperature $40^{\circ} \mathrm{C}$ and $50^{\circ} \mathrm{C}$ was determined for $4 \mathrm{~h}$ (Fig $5 \mathrm{a} \& \mathrm{~b}$ ). It was observed that EGI was highly stable at temperature $40-50^{\circ} \mathrm{C}$ for $3 \mathrm{~h}$ at $\mathrm{pH}$ 5.0. Though, EGII was found to be thermoacidophilic showing stable activity at $50-60^{\circ} \mathrm{C}$ for $3 \mathrm{~h}$ at $\mathrm{pH} 3.0$ but became inactive at $70^{\circ} \mathrm{C}$ after $30 \mathrm{~min}$ (Fig 6).

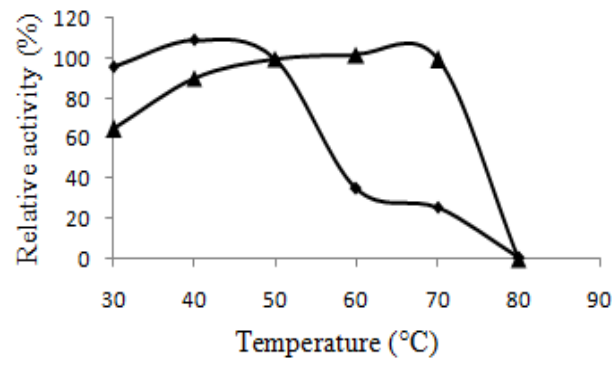

A

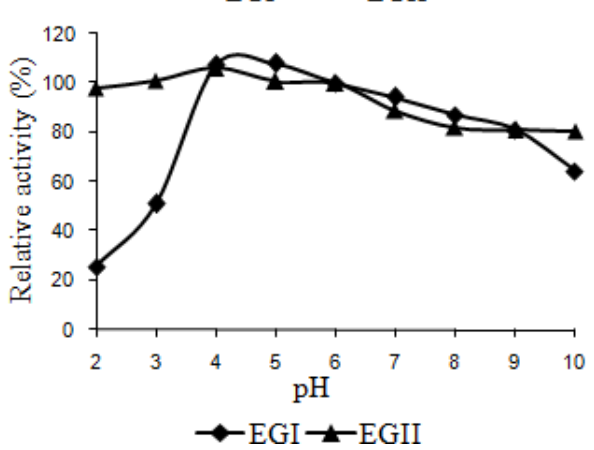

Fig. 4: Temperature (a) and pH (b) optima curve of EGI and EGII.
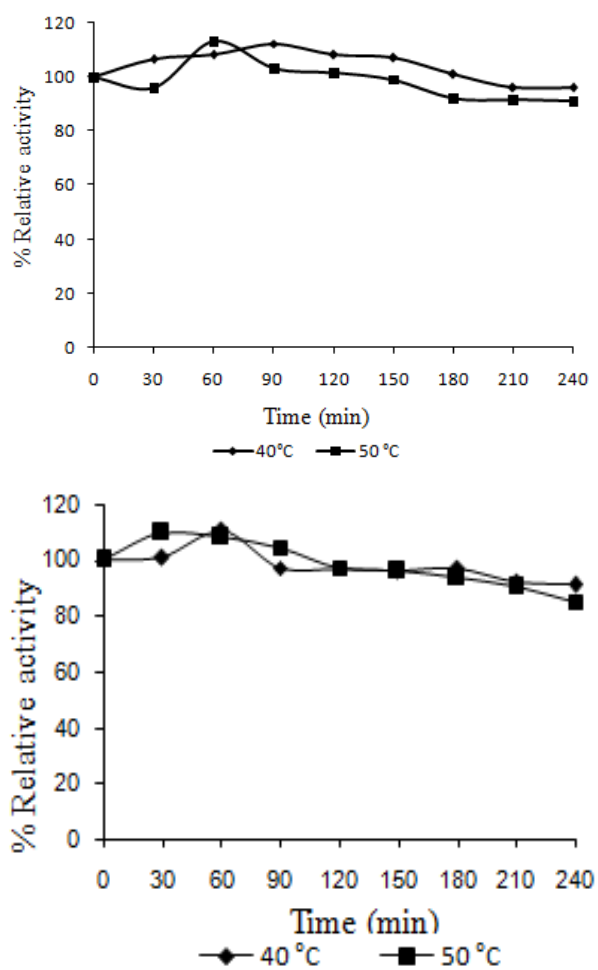

Fig. 5: Stability of EGI at different temperature at (a) $\mathrm{pH} 5$ and (b) $\mathrm{pH} 7$. 


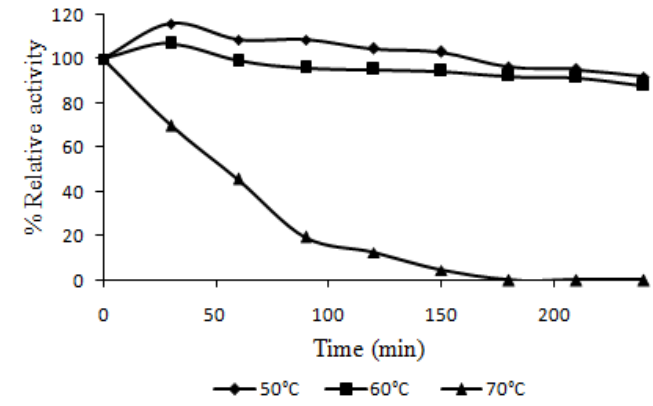

Fig. 6: Stability of EGII at different temperature at pH 3.0.

\subsection{Substrate specificity}

The results in Table 1 revealed the substrate specificity of purified EGI and EGII which were tested for different polysaccharides and aryl substrates. It was observed that EGI showed higher catalytic activity towards xyloglucan and barley $\beta$ glucan when compared to CMC.

Table. 1: Relative activities of EG and EGII on polysaccharides, Disaccharides, oligosaccharides and pNPs.

\begin{tabular}{lcc}
\hline Substrate & \multicolumn{2}{c}{ Relative activity (\%) } \\
& EGI & EGII \\
\hline CMC (low viscosity) & 100 & 100 \\
CMC(high viscosity) & - & - \\
Barley- $\beta$ - glucan & 106.9 & 101.4 \\
Xyloglucan & 112.5 & 59.8 \\
Laminarin & - & - \\
Lichenin & - & 15.6 \\
Polygalactouronic acid & - & - \\
Guargum & - & - \\
Xylan & - & - \\
Avicel & - & - \\
Cellobiose & 0.021 & - \\
Starch & - & - \\
Salicin & - & - \\
Sucrose & - & - \\
Filter paper & - & - \\
pNp-cellobioside & 46.7 & - \\
oNP- $\beta$-D-xylopyranoside & - & - \\
oNP- $\beta-D-$ galactopyranoside & - & - \\
pNP- $\beta$-D-galactopyranoside & - & - \\
pNP- $\alpha$-galactopyranoside & - & - \\
pNP- xylopyranoside & - & - \\
pNP-glucopyranoside & - & - \\
pNP-lactopyranoside & 78.08 & - \\
\hline
\end{tabular}

In addition, it showed $78.08 \%$ and $46.7 \%$ activity against $\mathrm{pNP}-\beta$ D-lactopyranoside and pNP-cellobioside as substartes and was therefore classified as a member of family GH7. Whereas, EGII showed almost similar affinity for barley $\beta$-glucan and CMC followed by xyloglucan and lichenan. Vlasenko \& co-workers [21] tested various EGs and observed only GH 7 and GH12 family found affinity for xyloglucan though they are not xyloglucanases but have active sites similar to those of GH16 xyloglucanases. Previously, two of seven cellulases from Chrysosporium lucknowense (Cel12A and Cel45A) have been reported to possess affinity towards xyloglucan together with activities towards CMC and barley $\beta$-glucan [22]. It was further observed that EGII was active against lichenan (with repeated units of $\beta, 1-3, \beta, 1-4$ linkages), but inactive against laminarin (with $\beta, 1-3$ linkages), which confirms preferential specificity of EGII towards $\beta, 1-4$ linkages. These results are in agreement with earlier observations made by Nazir et al [17]. Luo et al [23] reported the cloning of endo $\beta$-glucanase gene, belonging to family GH7, from Bispora Sp. MEY-1 and expressed in P.pastoris. The purified enzyme showed higher activity towards barley $\beta$-glucan and lichenan than CMC and also able to hydrolyze laminarin and oat spelt xylan suggesting that enzymes of same family from different microbial strains can differ in their substrate specificity. Moreover, the ability to hydrolyze different substrates can be explained by nonspecific bindings in the active site and/or by the presence of distinct catalytic domains, each one presenting a particular activity [24].

\subsection{Metal ions}

The effect of metal ions and chemicals on enzyme activity of EGI and EGII was investigated (Fig 7). It was found that all additives resulted in reduction of EG activity when compared to control. Activity of purified EGI and EGII was severly inhibited in the presence of DTT and mercaptoethanol indicating the presence of thiol groups at the active sites. The inhibitory effect of $\mathrm{Zn}^{2+}$ and $\mathrm{Cu}^{2+}$ metallic cations on EG activity is a common feature of cellulases. EGI showed $39 \%$ and $24 \%$ decrease in activity in the presence of SDS and PMSF whereas, EGII remained unaffected. As reported for other fungal endoglucanase, the purified enzymes showed inhibition for metallic cations which suggests the presence of at least one sulfahydryl group as cysteine in the active site, whose oxidation by the cations destabilizes the conformational folding of the enzyme [25]. The inhibition of activity of EGI and II in the presence of Nbromosuccinimide (NBS) suggests the presence of tryptophan residues in their active sites [26].

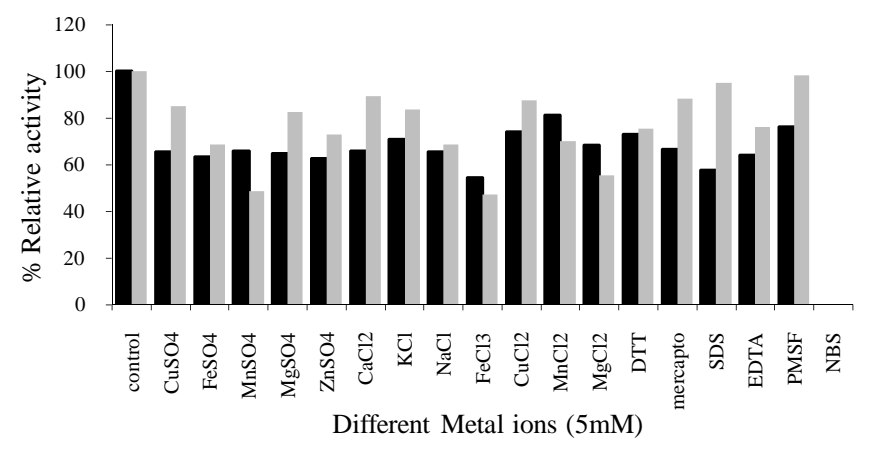

Fig. 7: Effect of metal ions and chemicals on activity of EGI and EGII.

\subsection{Kinetics}

The study also reports that EGI and EGII differed in their affinity towards substrates as evidence from kinetic studies (Table 2). Both isoforms have lower $\mathrm{Km}$ values for barley- $\beta$ glucan as compared to CMC thus indicating higher affinity of EGI and II towards barley - $\beta$-glucan than CMC. Furthermore, kinetics of EGI for xyloglucan was also carried out and observed lower $\mathrm{Km}(5.66 \mathrm{mg} / \mathrm{ml})$ in comparison to CMC as substrate. Nazir et al [17] reported the similar observations during characterization of purified endoglucanase from A.terreus. The Vmax of EGI and 
EGII for barley- $\beta$-glucan was estimated to be $0.46 \times 10^{2}$ and $0.59 \times$ $10^{2} \mu \mathrm{mol} \mathrm{min}-1 \mathrm{mg}$ protein $^{-1}$ respectively and was approximately 2.5 and 1.18 folds higher than that of CMC. Similarly Vmax of EGI for xyloglucan was calculated to be $0.37 \times 10^{2} \mu \mathrm{mol}$ min- 1 mg protein-1. Further, turnover number Kcat and catalytic efficiency $(\mathrm{Kcat} / \mathrm{Km})$ values of EGI and EGII were higher with barley- $\beta$-glucan, and xyloglucan as a substrate in case of EGI, than with CMC. Earlier reports also revealed that different endoglucanases differ in their affinity towards polysachharides as evident from the observed Km values [5]; [9].

Table. 2: Kinetics constants of EGI and EGII on different substrates.

\begin{tabular}{cccccc} 
Substrates & EG & & & & \\
CMC & EGI & 13.3 & $0.18 \times 10^{2}$ & $5.6 \times 10^{2}$ & $0.42 \times 10^{2}$ \\
Barley $\beta$ glucan & EGII & 4.54 & $0.50 \times 10^{2}$ & $11.0 \times 10^{2}$ & $2.42 \times 10^{2}$ \\
Xyloglucan & 3.5 & $0.46 \times 10^{2}$ & $1.4 \times 10^{2}$ & $4.0 \times 10^{2}$ \\
& EGII & 2.0 & $0.59 \times 10^{2}$ & $10.0 \times 10^{2}$ & $5.04 \times 10^{2}$ \\
& EGI & 5.66 & $0.37 \times 10^{2}$ & $11.5 \times 10^{2}$ & $2.03 \times 10^{2}$ \\
& EGII & $\mathrm{Nd}$ & $\mathrm{Nd}$ & $\mathrm{Nd}$ & $\mathrm{Nd}$ \\
\hline
\end{tabular}

\subsection{Hydrolysis}

Barley $\beta$-glucan composed of cellotriosyl/cellotetraosyl units separated by single (1-3)- $\beta$-linkage was employed as a substrate for elucidating the mode of action of endoglucanases [27]. The results in Fig 8a and b showed that purified EGI and EGII showed distinct mode of action.
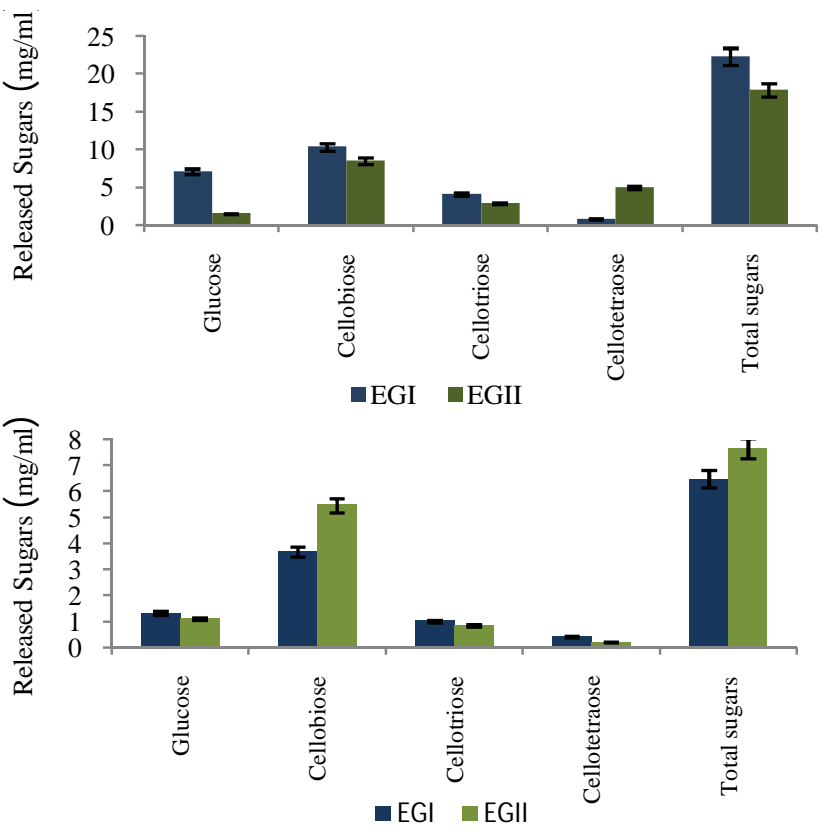

Fig. 8: Sugars obtained by the action of EGI and EGII from hydrolysis of (a) barley $\beta$-glucan and (b) $\mathrm{CMC}$

The HPLC profile indicated that EGI and EGII cleaves dp7 (Degree of Polymerization) oligosaccharide units of barley $\beta$ - glucan to release G3 (cellotriose) and G4 (cellotetraose) as the hydrolysis products (Fig 9a\&9b). Consequently, EGI cleaves G4 to G3 and G1 and eventually G3 to G2 (cellobiose) and G1 (glucose) as major products. Thus resulting in high levels of G2 $(10.3 \mathrm{mg} / \mathrm{ml})$ and $\mathrm{G} 1(7.1 \mathrm{mg} / \mathrm{ml})$ in the hydrolysate (Fig 8a). Whereas, EGII do not act effectively on G4 (which contain one $\beta$ 1-3 linkage) leading to its accumulation in the hydrolysate (Fig 9b). While, G3 is hydrolyzed to G2 and G1. However this difference in mode of action is not observed when CMC (Fig 8b) is used as a substrate which predominantly contains $\beta$ 1-4 linkages. The observed distinct mode of action observed in EGI from $A$. nidulans may have immense potential in production of fermentable sugars for biorefineries and in functional foods (prebiotics) production.
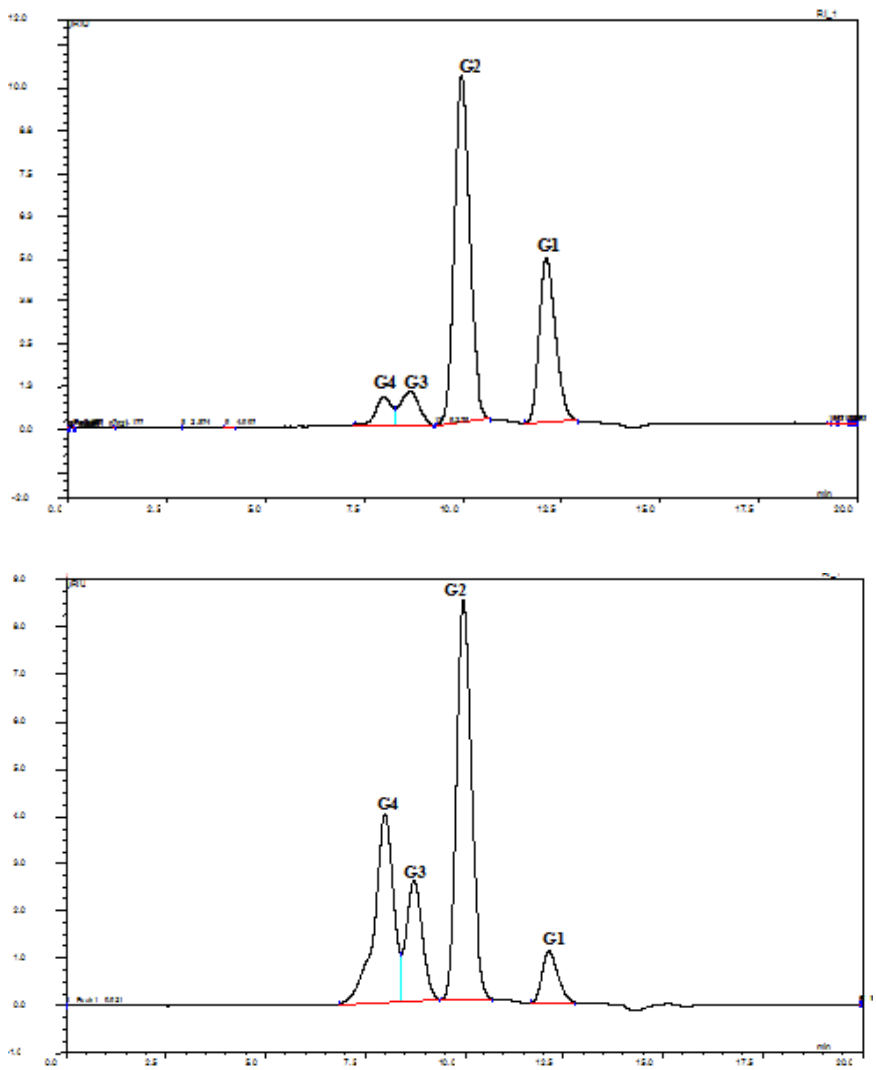

Fig. 9: HPLC chromatogram showing profile of hydrolysis obtained against barley $\beta$-glucan by the action of (a) EGI and (b) EGII.

\section{CONCLUSIONS}

Aspergillus nidulans seems to be a potentially important source of thermophilic and catalytically active endoglucanases $\mathrm{EGI}(\mathrm{GH} 7)$ and EGII(GH12), that can hydrolyze a variety of cellulosic substrates. such properties of endoglucanase make them promising candidates for biofuel and food industries.

\section{ACKNOWLEDGEMENT}

The financial support from NAIP (ICAR) for carrying out this research project (NAIP/ Comp-4/C-30030) "Novel 
biotechnological processes for production of high value products from rice straw and bagasse" is duly acknowledged.

\section{REFERENCES}

1. Saha, S., Roy, R., Sen, S.K., Ray, A.K. Characterization of cellulase producing bacteria from the digestive tract of tilapia, Oreochromis mossambica (Peters) and grass carp. (tenopharyngodon idella (Valenciennes). Aquaculture Research. 2006; 37(4):380-388. http://dx.doi.org/10.1111/j.1365-2109.2006.01442.x

2. Lynd, L.R., Weimer, P.J., Van Zyl, W.H., Pretorius, I.S. Microbial cellulose utilization: fundamental and biotechnology. Microbiology and Molecular Biology Reviews. 2002; 66(3): 506-507. http://dx.doi.org/10.1128/MMBR.66.3.506-577.2002

3. Ragothaman, M.Y., Andrew, J.R., Jeffrey, D.W., Tazez, Z.S. Thermostability in endoglucanase is fold specific. BMC Structural Biology. 2011; 11: 10. http://dx.doi.org/10.1186/1472-6807-11-10

4. Horn, S.J., Vaaje-Kolstad, G., Westereng, B., Eijsink, V.G. Novel enzymes for the degradation of cellulose. Biotechnology for Biofuels. 2012; 5: 45. http://dx.doi.org/10.1186/1754-6834$\underline{5-45}$

5. Narra, M., Dixit, G., Divecha, J., Kumar, K., Madamwar, D. and Shah, A.R. Production, purification and characterization of a novel GH12 family endoglucanase from Aspergillus terreus and its application in enzymatic degradation of delignified rice straw. 2014. International journal of Biodeterioration and Biodegradation. $\quad 2014 ; \quad 88$ : 150-161. http://dx.doi.org/10.1016/j.ibiod.2013.12.016

6. Soni, R., Nazir, A., Chadha, B.S. and Saini, H.S. Novel sources of fungal cellulases for efficient deinking of composite paper waste. Bioresources. 2008; 3: 234-246.

7. Kaur, B., Oberoi, H. and Chadha, B.S. Enhanced cellulase producing mutants developed from heterokaryotic Aspergillus strain. Bioresource Technology. 2014; 156: 100-107. http://dx.doi.org/10.1016/j.biortech.2014.01.016

8. Wang, K., Luo, H., Shi, P., Huang, H., Bai, Y. and Yao, Bin. A highly-active endo-1,3-1,4- $\beta$-glucanase from thermophilic Talaromyces emersonii CBS394.64 with application potential in the brewing and feed industries. Process Biochemistry. 2014; 49(9): 1448-1456. http://dx.doi.org/10.1016/j.procbio.2014.06.003

9. Sujit, S.J., Saurabh, S.D., Tae-SU, K., In-Won, K. and JungKul,L. Characterization of a novel endo- $\beta$-1,4-glucanase from Armillaria gemina and its application in biomass hydrolysis. Applied Microbiology and Biotechnology. 2013; 98:661-669.

10. Nakamura, A., Watanabe, H., Ishida, T., Uchihashi, T., Wada, M., Ando, T., Igarashi, K. and Samejima, M. Trade-off between processivity and hydrolytic velocity of cellobiohydrolases at the surface of crystalline cellulose. Journal of the American Chemical Society. 2014; 136(12):5484-4592. http://dx.doi.org/10.1021/ja4119994
11. Sharma, M., Chadha, B.S, Kaur, M., Ghatora, S.K. and Saini, H.S. Molecular characterization of multiple xylanase producing thermophilic/thermotolerant fungi isolated from composting materials. Letters in Applied Microbiology. 2008; $46 \quad$ (5):526-535. http://dx.doi.org/10.1111/j.1472765X.2008.02357.x

12. Bradford, M.M. A rapid and sensitive method for the quantification of microgram quantities of protein utilizing the principle of protein-dye binding. Analytical Biochemistry. 1976; 72 (1-2):248-254. http://dx.doi.org/10.1016/00032697(76)90527-3

13. Miller, G.L. Use of dinitrosalicylic acid reagent for determination of reducing sugars. Analytical Chemistry. 1959; 31 (3):426-428. http://dx.doi.org/10.1021/ac60147a030

14. Kenneth, M.B., Alejandrro, P.R., Xin-Liang, L., Siqing, L. and Stephen, R.H. Purification and characterization of a family 5 endoglucanase from a moderately thermophilic strain of Bacillus licheniformis. Biotechnology Letters. 2006; 28: 17611765. http://dx.doi.org/10.1007/s10529-006-9153-0

15. Kaur,B., Sharma, M., Soni, R., Oberoi, H. and Chadha, B.S. Proteome based profiling of hyper-cellulase producing strains developed through inter-specific protoplast fusion between Aspergillus nidulans and Aspergillus tubingensis. Applied Biochemistry and Biotechnology. 2013; 169 (2):393-407. http://dx.doi.org/10.1007/s12010-012-9985-0

16. Kaur, J., Chadha, B.S., Kumar, B.A. and Saini, H.S. Purification and characterization of two endoglucanases from Melanocarpus Sp. MTCC 3922. Bioresource Technology. 2007; $98 \quad$ (1):74-81. http://dx.doi.org/10.1016/j.biortech.2005.11.019

17. Nazir, A., Soni, R., Saini, H.S., Manhas, R.K. and Chadha, B.S. Purification and caharacterization of an endoglucanase from Aspergillus terreus highly active against barley $\beta$-glucan and xyloglucan. World Journal of Microbiology and Biotechnology. 2009; 25(7):1189-1197. http://dx.doi.org/10.1007/s11274-009-0001-y

18. Pol, D., Laxman, R.S. and Rao, M. Purification and biochemical characterization of endoglucanase form Penicillium pinophilum MS 20. Indian Journal of Biochemistry and Biophysics. 2012; 49(3):189-194.

19. Begum, F., Absar, N. and Alam, S.M. Purification and characterization of extracellular cellulase from A.oryzae ITCC4857.01. Journal of Applied Sciences and Research. 2009; 5(10): 1645-1651.

20. Tavers, E.Q de Pinho., Rubini, M.R., Mello-de-Sousa, T.M., Duarte, G.C., Paula de Faria, F., Filho, E.X.F., Kyaw, C.M., Pereira, I.S. and Pocas-Fonseca, M.J. An acidic thermostable recombinant Aspergillus nidulans endoglucanase is active towards distinct agriculture residues. Enzyme Research. 2013; http://dx.doi.org.1155/2013/287343.

21. Vlasenko, E., Schulein, M., Cherry, J. and Xu, F. Substrate specificity of family 5,6,7,9,12 and 45 endoglucanases. Bioresource Technology. 2010; 101(7):2405-2411. http://dx.doi.org/10.1016/j.biortech.2009.11.057 
22. Bukhtojarov, F.E, Ustinov, B.B., Salanovich, T.N., Antonov, A.I., Gusakova, V. and Sinitsyn, A.P. Cellulase complex of the fungus Chrysosporium lucknowense: isolation and characterization of endoglucanase and cellobiohydrolases. Biochem. Mosc. 2004; 69(5):542-551. http://dx.doi.org/10.1023/B:BIRY.0000029853.34093.13

23. Luo, H., Yang, J., Yang, P., Li, Huang, H., Shi, P., Bai, Y., Wang, Y., Fan, Y. and Yao, B. Gene cloning and expression of a new acidic family 7 endo- $\beta$-1,3-1,4-glucanase from the acidophilic fungus Bispora Sp. MEY-1. Applied Microbiology and Biotechnology. 2010; 85(4):1015-1023. http://dx.doi.org/10.1007/s00253-009-2119-0

24. Van Dyk, J.S. and Pletschke, B.I. A review of lignocelluloses bioconversion using enzymatic hydrolysis and synergistic cooperation between enzymes-factors affecting enzymes, conversion and synergy. Biotechnology Advances. 2012; 30(6):1458-1480. http://dx.doi.org/10.1016/j.biotechadv.2012.03.002

25. Rouvinen, J., Berfors, T., Teeri T., Knowles, J.K. and Jones, T.A. Three dimensional structure of cellobiohydrolase II from Trichoderma reesei. Science. 1990; 249(4967):380-386. http://dx.doi.org/10.1126/science.2377893
26. Adsul, M.G., Bastawde, K.B. and Gokhale, D.V. Biochemical characterization of two xylanases from yeast Pseudozyma hubeiensis producing only xylooligosaccharides. Bioresource Technology. 2009; 100(24):6488-6495. http://dx.doi.org/10.1016/j.biortech.2009.07.064

27. Andersson, A.A.M., Armo, E., Grangeon, E., Fredriksson, H., Andersso, R. and Aman, P. Molecular weight and structure units of (1-3, 1-4)- $\beta$-glucans in dough and bread made from hull-less barley milling fractions. Journal of cereal Science. 2004; 40(3):195-204. http://dx.doi.org/10.1016/i.jcs.2004.07.001

\section{How to cite this article:}

Baljit Kaur, H.S. Oberoi, B.S. Chadha. Comparative analysis of two catalytically distinct endoglucanases from Aspergillus nidulans. J App Biol Biotech. 2015; 3 (02): 022-029. 